UDC 347.1

LBC 67.404

\title{
MORALITY AND LAW AS THE BASIS OF LEGAL EDUCATION AND VALID IMPLEMENTATION OF CIVIL RIGHTS
}

\author{
Tatiana V. Deryugina \\ Volgograd Institute for the Humanities, Volgograd, Russian Federation
}

Anton O. Zaitsev

Moscow State University, Moscow, Russian Federation

\begin{abstract}
Introduction: morality is the most essential basis for a person's upbringing as an individual. Any social, including legal ones phenomena are reflected in the human mind. Legal ideas affect the formation of the motives and lines of behavior in the legal sphere, but through the legal regulation of the individual behavior an active role of law and legal consciousness shows itself. Moral values, standards, principles and ideals perceived by a person lie at the basis of legal consciousness. The morality of a person is an internal restrictor of their legal consciousness. It forms the legal consciousness in a way that it does not allow the person to exercise their rights to the detriment of third parties, the society and the state. The objective is to analyze the effect of moral categories on the level of forming legal consciousness and exercising civil rights. The study methods used are the following: a general method (dialectical materialism); scientific methods (logical (induction, deduction, analysis and synthesis), system, functional); private law methods (formal and legal, comparative legal). Results: there have been considered the questions of influence of the internal and external factors on the formation of a person and their legal consciousness (the system of biogenetic, social and psychosocial factors (motivation of behavior, the way of relating their interests with public ones, beliefs, values and dignity, duty, responsibility, conscience, moral and aesthetic principles, and so on). There has been raised the problem of correlation of legal and moral education of the individual, justified their mutual influence, as well as the impact on the implementation of civil rights. Conclusions: there have been made the conclusions on the formation of a moral personality "outside", through the mechanism of education, and "inside", through the personal qualities. It has been proved that the content, methods, and ways of this forming depend on the level of the economic, political, legal, cultural development of the society. There have been systematized the factors influencing the formation of legal consciousness in matter and scope. There have been obtained the typological groups with different levels of legal education and legal consciousness. There has been substantiated the influence of moral norms on the implementation of civil rights.
\end{abstract}

Keywords: morality, integrity, justice, legal education, legal consciousness, implementation limits, civil right.

УДК 347.1

ББК 67.404

НРАВСТВЕННОСТЬ И ПРАВО КАК ОСНОВЫ ПРАВОВОГО ВОСПИТАНИЯ И ПРАВОМЕРНОГО ОСУЩЕСТВЛЕНИЯ СУБЪЕКТИВНЫХ ГРАЖДАНСКИХ ПРАВ

\author{
Татьяна Викторовна Дерюгина
}

Волгоградский гуманитарный институт, г. Волгоград, Российская Федерация

Антон Олегович Зайцев

Московский государственный университет, г. Москва, Российская Федерация 
Введение: нравственность является важнейшей основой воспитания человека как личности. Любые социальные, в том числе правовые явления отражаются в сознании человека. Правовые представления воздействуют на формирование мотивов и установок поведения в правовой сфере, а через регулирование правового поведения личности проявляется активная роль права, правосознания. Нравственные ценности, нормы, принципы и идеалы, воспринятые субъектом, лежат в основании правосознания. Нравственность личности - это внутренний ограничитель правосознания. Она формирует правосознание таким образом, что не позволяет субъекту использовать свои права во вред третьим лицам, обществу и государству. Цель исследования: проанализировать влияние нравственных категорий на уровень формирования правосознания и осуществления субъективных гражданских прав. При проведении исследования использовались методы: всеобщий метод (диалектический материализм); общенаучные методы: логический (индукции, дедукции, анализа и синтеза), системный, функциональный; частноправовые методы: формально-юридический, сравнительно-правовой. Результаты: рассмотрены вопросы влияния на формирование личности и ее правосознание внутренних и внешних факторов (системы биогенетических, социальных и психосоциальных факторов: мотивация поведения, способ соотнесения своих интересов с общественными, убеждения, ценностные ориентации, а также чувство собственного достоинства, долг, ответственность, совесть, нравственноэстетические принципы и т. д.). Подняты проблемы соотношения правового и нравственного воспитания личности, обосновано их взаимное воздействие, а также влияние на осуществление субъективных гражданских прав. Обоснованы выводы о формировании нравственной личности «извне» через механизм воспитания и «изнутри» через личностные качества. Доказано, что содержание, способы и методы формирования зависят от уровня экономического, политического, правового, культурного развития общества. Систематизированы факторы, влияющие на формирование правосознания, по содержанию и сфере действия. Выделены типологические группы с различным уровнем правового воспитания и правосознания. Обосновано влияние нравственных норм на осуществление субъективных гражданских прав.

Ключевые слова: нравственность, добросовестность, справедливость, правовое воспитание, правосознание, пределы осуществления, субъективное гражданское право.

\section{Введение}

Надлежащее осуществление субъективных гражданских прав регулируется нормативными правовыми актами, которые допускают определенную свободу - возможность свободного выбора вариантов поведения. Таким образом государство посредством права устанавливает границы свободы индивида, создает внешнюю направленность его деятельности. В каждый исторический момент право формирует для субъекта границу возможного и невозможного поведения.

Однако важнейшую роль в осуществлении субъективных прав играют и внутренние характеристики субъекта, его личностные качества, представления о добре и зле, справедливости и несправедливости, добросовестности и недобросовестности. Любые правовые явления отражаются в сознании человека, и к таким явлениям складывается определенное отношение. Правовые представления воздействуют на формирование мотивов и установок поведения в правовой сфере, а через регулирование правового поведения личности проявляется активная роль права, правосознания.
Нравственные основы, как и основные правовые представления о правах, обязанностях, ответственности, закладываются у человека с детства. Но знать законы мало, необходимо воспитать ребенка в духе неукоснительного соблюдения закона; важно сформировать верное понимание права и его роли в жизни общества, его ценности и необходимости.

Цель правового воспитания - сформировать человека, знающего и уважающего закон, противодействующего правонарушениям, правовому нигилизму, коррупции и т. п. Для осуществления этой цели необходимо, чтобы человек имел высокие нравственные идеалы.

Основная функция нравственности - функция регулятора социального поведения (регулятивная функция), основной целью реализации которой в праве как раз и является установление параметров осуществления субъективных прав.

\section{Нравственные законы и их влияние на формирование правомерного поведения}

Нравственность следует рассматривать в двух аспектах: как внутреннее отношение 
субъекта к своему поведению и поведению третьих лиц, пропускаемое через призму его представлений о моральности, и как категория, получившая внешнее выражение в нормах права, а следовательно, не только обусловливающая определенное поведение, но и предусматривающая определенные неблагоприятные последствия отклонения от такого поведения. На этом этапе происходит трансформация внутренних представлений субъекта во внешние, так как возведенные в закон нравственные принципы уже не могут являться только внутренними границами поведения конкретного субъекта, а становятся волей государства, возведенной в закон. И здесь возникает проблема соотношения права и нравственности, которая всегда вызывала много дискуссий.

Являясь всеобщими и универсальными, нравственные законы должны быть признаны всеми, каждый субъект должен осознать необходимость руководствоваться ими в интеpecax как всего общества, так и каждого из его членов. Можно ли добиться такого состояния в обществе? Думается, ответ отрицательный. Причины такого ответа видятся в следующем.

Bo-nервыx, на самого человека при его формировании оказывает влияние сложная система биогенетических, социальных и психосоциальных факторов (мотивация поведения, способ соотнесения своих интересов с общественными, убеждения, ценностные ориентации, а также чувство собственного достоинства, долг, ответственность, совесть, нравственно-эстетические принципы и т. д.). Так, к факторам, влияющим на формирование нравственности личности, ученые-психологи и социологи относят: воспитание, образование, круг общения, жизненный опыт, интересы и потребности субъекта, которые выступают основой активности личности, религию, культуру [3, с. 67-81], материальное положение, характер труда, самоидентификацию, национальность [1, с. 52-53], семью, наследственность, мировоззрение, ценностные ориентации, веру и убеждения, условия внешней среды (социально-политические, исторические традиции) [9, с. 330, 332, 372], уровень образования профессиональных знаний, правосознание $[4$, c. 8,13$]$. Кроме того, на формирование оце- ночных категорий того или иного индивида влияет принадлежность субъекта к определенной типологической группе. Так, выделяют рядовую личность, которая характеризуется стандартным поведением; значительную личность, имеющую в активе социально и духовно значимое поведение; исторические личности - те люди, которые существенно повлияли на ход истории; выдающаяся личность историческая личность, которая своими действиями способствовала историческому развитию общества. Помимо приведенных выделяют мифологический, религиозный, идеологический, ценностный тип и т. д.

Индивидуальное развитие человека заключается в ассимиляции им социальных условий и обретении собственного места в социуме. Человек мыслит, чувствует, действует как представитель общества, независимо от того, осознает он этот факт или нет. Но он также обладает уникальной способностью субъективно относиться к окружающей его реальности. При этом на него оказывают влияние внешние и внутренние факторы. Внешние - социум и природа. Внутренние - сознание, воля, чувства и т. д. Поэтому поступки каждого человека сугубо индивидуальны. Но субъективное отношение человека к действительности есть не только результаты работы данных факторов, но и процесс работы человека над собой (или отсутствие такой работы).

Человек, будучи элементом социальной среды, наделен умом, волей, чувствами, он не сводим только к социальной среде, он существо лично-общественное. Человек не просто воспринимает внешние факторы окружающей среды, он их оценивает, формирует собственное отношение, основанное на внутренних представлениях и характеристиках данного субъекта.

Факторы, влияющие на формирование нравственности, условно можно разделить на внешние и внутренние, где уровень развития техники, технологий, организацию процесса труда и присвоения, образование, круг общения, религию, культуру, воспитание можно отнести к внешним, которые, в свою очередь, влияют и формируют внутренние. Среди внешних мы также можем выделить материальные и духовные факторы. Под влиянием вне- 
шних для индивида факторов социальной среды происходит воспитание человека, нормы и правила общежития предъявляются ему как обязательные, подкрепляемые поощрением или принуждением. К внутренним факторам можно отнести уровень культуры самого индивида, мировоззрение, ценностные ориентации, веру, убеждения и т. д. Именно с помощью этих факторов человек оценивает свое поведение и поведение других людей.

Bo-вторых, сформировавшиеся нравственные качества не остаются неизменными. В процессе жизнедеятельности человек формирует и корректирует свои установки, интересы, потребности, свою деятельность. Важнейшую роль в данном процессе играют уже сложившиеся внутренние установки человека - стыд, честь, страх, совесть и т. д. Однако если страх имеет биологическую природу и корректирует деятельность индивида в отношении внешней среды (например, страх наказания за возможное правонарушение), то стыд, честь, совесть и т. д. - осознанные средства самоконтроля.

$B$-третьих, сущность человека не абстрактна, а конкретно-исторична, то есть содержание ее, оставаясь социальным, изменяется в зависимости от конкретного содержания эпохи. Человек обладает сущностью, которая допускает его деятельность в пределах системы возможностей, которые исторически определены и ограничены. Личность есть обладающий самосознанием и мировоззрением человек, достигший понимания своих социальных функций, своего места в мире, осмысливающий себя как субъекта исторического творчества, как звено цепи поколений. Личность есть индивидуальное сосредоточие и выражение общественных отношений и функций людей, субъект познания и преобразования мира, прав и обязанностей, этических, эстетических и иных социальных норм, в том числе юридических.

Каждый человек - это индивидуальное явление, способное к самостоятельной жизни, саморегулированию, сохранению своей устойчивости. Человеческая индивидуальность характеризуется целостностью, обособленностью, неповторимостью, автономностью, творчеством и т. д. Соответственно набор моральных ценностей у каждого индиви- да свой, но обособление личности возможно лишь в обществе.

Поэтому, признавая индивидуальность и неповторимость каждого человека, следует помнить, что каждое свойство личности, ее неповторимость включает в себя признаки, имеющие всеобщую общественную природу. И двуединство общего и индивидуального выступает как один из внутренних источников формирования личности и пределов ее поведения, не только повседневного, но и правового.

Учитывая это, верно утверждать, что в зависимости от исторического периода меняется не только нравственная характеристика отдельной личности, но и в целом нравственные устои общества. Например, английские суды вплоть до середины XIX в. признавали действительными договоры о пари на продолжительность жизни отцов [5], что в настоящее время считается безнравственным. Во Франции вплоть до 1818 г. в судебной практике договоры страхования жизни рассматривали как недействительные по мотиву их безнравственности [7, с. 106]. Однако вслед за тем они получили широкое распространение не только во Франции, но и в других странах, включая Россию.

$B$-четвертых, нравственность человека обусловлена типом цивилизации, к которой он принадлежит. Так, восточная цивилизация ориентируется на коллективизм, традиционализм, адаптацию к среде. В связи с этим основными ценностями считаются культ общины, почитание родителей, авторитаризм и т. д. Западная цивилизация имеет в основе индивидуализм, культ личности, адаптирование среды к интересам человека. Поэтому основополагающими ценностями выступают свобода, индивидуальность, равноправие и т. д. Западное правосознание предполагает юридическую активность личности. В евразийской цивилизации сочетаются элементы западной и восточной цивилизаций. Так, русскому народу как представителю данной группы свойственны коллективизм, патриотизм, взаимопомощь, открытость, терпимость, духовность, анархичность и т. д. [2, с. 340-344]

$B$-nятых , нравственность национальна. При начале всякого народа, всякой национальности идея нравственности всегда предше- 
ствовала зарождению национальности, ибо она же и создала еe $[8$, с. 124]. Быть нравственным - значит жить согласно нравам своей страны [6, с. 45].

\section{Выводы}

Таким образом, формирование нравственной личности идет «извне» через механизм воспитания и «изнутри» через личностные качества. Содержание, способы и методы формирования зависят от уровня экономического, политического, правового, культурного развития общества. Поэтому наиболее сходными представлениями о нравственных нормах обладают представители одной национальности, одного государства и одной религии. Внутри этой группы наиболее сходными представлениями о нравственных нормах обладают личности, относящиеся к одной социальной группе, классу, профессии. В свою очередь внутри этой группы выделяются возрастные группы, группы по уровню образования и уровню дохода.

Все выявленные факторы можно классифицировать по содержанию на материально-экономические (производственные и бытовые), социально-политические (статус человека в обществе, семья), индивидуально-личностные (возраст, образование, мировоззрение, ценностные ориентации, вера и убеждения) и духовные (культура, исторические традиции); по сфере действия на индивидуальные, групповые (классовые, этнические, конфессиональные) и общечеловеческие.

Право и нравственность тесно связаны, они совместно регулируют общественные отношения, позитивно влияя на личность и общество. Право есть инструмент реализации в жизни общества определенного нравственного идеала. С этой точки зрения право должно быть морально обосновано, иметь своего рода легитимацию с позиций господствующей общепринятой морали. Однако, как всякий инструмент, право может быть использовано как с пользой, так и во зло.

Нравственные законы должны быть признаны всеми, каждый субъект должен осознать необходимость руководствоваться ими в интересах как всего общества, так и каждого из его членов. Однако применять нрав- ственные нормы можно только зная и осознавая их.

Одним из основных признаков нравственности является добровольность осуществления ее норм. И важную роль здесь играет не только уровень воспитания, образования, культуры и т. д., но и правосознание самого субъекта правоприменения.

Правосознание человека напрямую связано с нравственным сознанием. Нравственные ценности, нормы, принципы и идеалы, воспринятые субъектом, лежат в основании правосознания. Нравственность личности - это внутренний ограничитель правосознания. Она формирует правосознание таким образом, что не позволяет субъекту использовать свои права во вред третьим лицам, обществу и государству.

Право и мораль образуют единую систему социальных норм, регулирующих поведение людей в обществе. Они имеют единые цели - достижение справедливости, единый объект воздействия - общественные отношения и единую функцию - регулирование общественных отношений. И право, и мораль устанавливают пределы осуществления субъектами своих гражданских прав.

\section{СПИСОК ЛИТЕРАТУРЫ}

1. Беленький, В. Х. Социальная структура российского общества: состояние и проблемы теоретической разработки / В. Х. Беленький // Социологические исследования. - 2006. - № 11 (271). - С. 49-57.

2. Бердяев, Н. А. Русская идея. Судьба России /Н. А. Бердяев. - М. : Изд-во В. Шевчук, 2000. -541 с.

3. Бузский, М. П. Субъектная основа бытия и регулирования общества / М. П. Бузский. - Волгоград : Изд-во ВолГУ, 2002. -248 с.

4. Васильчук, Ю. А. Социальное развитие человека. Фактор социума / Ю. А. Васильчук // Общественные науки и современность. - 2004. - № 1. C. 5-16.

5. Вольф, М. Международное частное право / М. Вольф. - М. : Гос. изд-во иностр. лит., 1948. $178 \mathrm{c}$.

6. Гегель, Г. Работы разных лет. В 2 т. / Г. Гегель. - М. : Мысль, 1973. - 789 с.

7. Годэмэ, Е. Общая теория обязательств /Е. Годэмэ. - М. : Изд-во Минюста СССР, 1948. - 234 с.

8. Достоевский, Ф. Мысли, высказывания, афоризмы / Ф. Достоевский. - Париж : Пять континентов, 1975. - 1145 c. 
9. Спиркин, А. Г. Философия / А. Г. Спиркин. -2-е изд. - М. : Гардарики, 2003. - 736 с.

\section{REFERENCES}

1. Belenkiy V.Kh. Sotsialnaya struktura rossiyskogo obshchestva: sostoyanie i problemy teoreticheskoy razrabotki [Social Structure of Russian Society: Condition and Problems of Theoretical Development]. Sotsiologicheskie issledovaniya, 2006, no. 11 (271), pp. 49-57.

2. Berdyaev N.A. Russkaya ideya. Sudba Rossii [Russian Idea. The Fate of Russia]. Moscow, Izd-vo V. Shevchuk, 2000. 541 p.

3. Buzskiy M.P. Subyektnaya osnova bytiya $i$ regulirovaniya obshchestva [The Subjective Ground of Being and Community Control]. Volgograd, Izd-vo VolGU, 2002. 248 p.
4. Vasilchuk Yu.A. Sotsialnoe razvitie cheloveka. Faktor sotsiuma [Social Development Rights. Society Factor]. Obshchestvennye nauki i sovremennost, 2004, no. 1, pp. 5-16.

5. Volf M. Mezhdunarodnoe chastnoe pravo [Private International Law]. Moscow, Gos. izd-vo inostr. lit., $1948.178 \mathrm{p}$.

6. Gegel G. Raboty raznykh let. V 2 t. [Works of Different Years. In 2 vols.]. Moscow, Mysl Publ., 1973. $789 \mathrm{p}$.

7. Godeme E. Obshchaya teoriya obyazatelstv [The General Theory of Obligations]. Moscow, Izd-vo Minyusta SSSR, 1948. 234 p.

8. Dostoevskiy F. Mysli, vyskazyvaniya, aforizmy [Sayings, Proverbs, Aphorisms]. Paris, Pyat kontinentov Publ., 1975. 1145 p.

9. Spirkin A.G. Filosofiya [Philosophy]. 2nd ed. Moscow, Gardariki Publ., 2003. 736 p.

\section{Information About the Authors}

Tatiana V. Deryugina, Doctor of Juridical Sciences, Professor, Pro-rector for Research, Volgograd Institute for the Humanities, Gribanova St., 12, 400011 Volgograd, Russian Federation, sofija96@mail.ru, rektor@vggi.ru.

Anton O. Zaitsev, Third-Year Student of Law Faculty, Moscow State University, Leninskie gory, 1, GSP-1, p. 13-14, 4th Academic Building, 119991 Moscow, Russian Federation, lara7@bk.ru, postmaster@econ.msu.ru.

\section{Информация об авторах}

Татьяна Викторовна Дерюгина, доктор юридических наук, профессор, проректор по научной работе, Волгоградский гуманитарный институт, ул. Грибанова, 12, 400011 г. Волгоград, Российская Федерация, sofija96@mail.ru, rektor@vggi.ru.

Антон Олегович Зайцев, студент третьего курса юридического факультета, Московский государственный университет, ул. Ленинские горы, 1, ГСП-1, стр. 13-14, 4-й учебный корпус, 119991 г. Москва, Российская Федерация, lara7@bk.ru, postmaster@econ.msu.ru. 